\title{
The effect of virtual reality distraction on reducing patients' anxiety before coronary angiography: a randomized clinical trial study
}

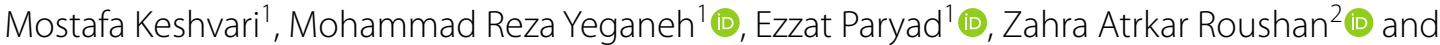 \\ Moluk Pouralizadeh ${ }^{1,3^{*}}$ (1)
}

\begin{abstract}
Background: Coronary angiography is used as a qualified method to diagnose coronary heart disease. However, patients undergoing coronary angiography experience a great deal of anxiety. The present study is aimed at investigating the effect of virtual reality on anxiety before coronary angiography. In a randomized controlled trial, 60 candidates for coronary angiography were randomly assigned to two intervention and control groups from April to July 2019. Data were collected by Spielberger's situational anxiety questionnaire. The participants' anxiety level and their heart rate, respiratory rate, and blood pressure were measured before and immediately after the intervention. The Intervention group received virtual reality intervention, and the control group was cared for based on the hospital routine. Data were entered into the SPSS version 24.0 software (SPSS Inc.) and analyzed using Chi-square, Paired samples, and independent sample $t$ tests.
\end{abstract}

Results: The majority of participants were male (71.25\%) and the Mean \pm SD age of them in the intervention and control groups was $50.95 \pm 4.120$ and $52.08 \pm 4.002$ years, respectively. The mean score of anxiety $(p<0.01)$, heart rate $(p=0.001)$, and systolic blood pressure $(p=0.016)$ after the intervention in the intervention group decreased significantly.

Conclusions: This study indicated the implementation of a VR distraction protocol in the patients could effectively reduce perioperative anxiety and its indices. It showed that VR is a safe method without any complications related to the device and with good acceptability.

Registration code IRCT201 40515017693N3.

Keywords: Virtual reality, Angiography, Anxiety state, Vital signs, Heart diseases

\section{Background}

Nowadays coronary heart disease (CHD) is one of the most common non-communicable diseases worldwide [1]. It is the largest cause of death in many developed countries. However, the majority of the deaths due to CHD occurred in developing countries with a mortality

\footnotetext{
*Correspondence: pouralizadehm@gmail.com

${ }^{3}$ Shahid Dr. Beheshti Nursing and Midwifery School, Hamidyan suburb,Shahid Beheshti Ave., Guilan, Rasht, Islamic Republic of Iran Full list of author information is available at the end of the article
}

rate of 220.8 cases per 100,000 people [2]. In Iran in a cohort study, high incidence rates were reported for cardiovascular disease mortality in both men and women [3].

Coronary artery angiography is used as a qualified method to diagnose CHD. It is also a gold standard technology to find the most appropriate treatment method [4]. However, angiography is an important cause of anxiety in cardiac patients, and $82 \%$ of patients undergoing angiography experience preoperative anxiety [5, 6]. A high percentage of patients with anxiety develop 
chest pain [7]. Anxiety can increase the risk of coronary artery spasm, tachycardia, hypertension, and cardiac dysrhythmias. According to the studies, severe anxiety is associated with decreased immunity and cardiovascular dysfunctions $[6,8,9]$. Moreover, because an anxious patient is less likely to collaborate with health care providers, technical problems might occur during coronary artery angiography [10].

Previous studies have shown that patients undergoing cardiac angiography experience a great deal of anxiety. Moreover, these patients receive inadequate and inappropriate care $[11,12]$. Different interventions before the angiography can increase the patient's tolerability to procedural discomforts. As one of the major interventions of nurses is to relieve patients' discomfort, therefore they should assess and control the anxiety using noninvasive methods [5].

Distraction by Virtual Reality (VR) is an effective noninvasive technique that reduces the physical and psychological discomforts in patients. The term $V R$ was popularized in the late 1980 s by Jaron Lanier, one of the pioneers of the field [13]. The Encyclopaedia Britannica defined VR as "the use of computer modeling and simulation that enables the person to interact with an artificial three-dimensional (3-D) visual or another sensory environment" [14]. Some studies indicated VR is a valuable new technology that provides a better mental preparedness for adults and pediatrics that undergoing invasive procedures using distraction techniques [15-19]. However, the other studies showed contradictory results about the effectiveness of VR on patients' anxiety $[17,20$, 21]. Certainly, the information about the effectiveness of VR on the psychosocial status of patients waiting for coronary artery angiography is scarce. Considering the importance of reducing anxiety in patients with CHD, administrating interventions such as VR might be effective in improving anxiety. Previous studies have demonstrated the application of VR to reduce anxiety in numerous medical settings such as dental hygiene clinics [22], bone marrow aspiration in an outpatient cancer center [22], hand injury requiring surgical wound care [23]. However, the review of the literature revealed that so far no study has investigated the effects of VR on the anxiety of the patients before coronary artery angiography in Iran.

\section{Objective}

The present study is aimed at investigating the effect of virtual reality on anxiety before coronary angiography in patients referred to the cardiovascular, Medical, and Research Center of Guilan University of Medical Sciences.

\section{Methods}

\section{Trial design}

This was a single-center, randomized, controlled trial on the efficacy of VR on anxiety levels in patients candidates for coronary artery angiography. The CONSORT guidelines and the checklist was used for reporting this trial and the description of the interventions. The study contained one intervention and a control group and followed a pretest-posttest design. Each group consisted of 40 patients.

\section{Study setting}

The study was conducted at the school of nursing and midwifery, Guilan University of Medical Sciences, Rasht, Iran. Patients were enrolled from April to July 2019 in Heshmat hospital that is the central cardiac hospital at Guilan University of Medical Sciences.

\section{Participants}

Patients candidates for diagnostic coronary artery angiography through radial artery participated in this study. Eighty participants meeting the inclusion criteria were randomly assigned to one of two groups intervention (VR) and control. The participants were recruited through the angiography department in the Heshmat Cardiac Disease Hospital that was an outpatient setting. Inclusion criteria included the tendency to participate in the study, the first experience of angiography, patients without a history of neurological impairment (such as motor, visual and auditory disabilities), psychological disorders, and taking sedatives. Patients receiving psychological drugs were not included in the study. Also, the candidates were excluded if they had suffered from an inability to tolerate the virtual reality and the occurrence of anxiety symptoms such as fear of closed space. The eligible patients were identified and informed about the study objectives. After giving their preliminary informed written consent to participating in the study, the candidates were offered detailed information and had the opportunity to ask the questions of the study instrument.

\section{Instruments}

To collect the data, a personal information form and the short form of Spielberger's situational anxiety questionnaire were used.

\section{Personal information form}

The Personal Information Form included two parts. The first part was demographic characteristics included seven questions: patient's age, gender, marital status, educational level, job title, life place, and having an experience of virtual reality. The second part included clinical indices of blood pressure, respiratory rate, and heart rate. 
Short form of Spielberger state-trait anxiety inventory (STAI) The short form of Spielberger State-Trait Anxiety Inventory (STAI) was used to measure the level of anxiety before and after angiography [24]. This Inventory is a tool used to determine the level of state-trait anxiety and included 6-items. The STAI assesses what is felt at the time of measurement. The scoring of this scale is on a four-point Likert as follows: (1) very low, (2) low, (3) high (4) very high. The range of anxiety scores is between 6 and 20. A higher score indicates greater anxiety. In the current study, Cronbach's alpha coefficient of the scale was found to be 0.80 for pre-angiography and 0.82 for post-angiography.

\section{Sample size}

Sample size calculation was based on the anxiety scores in a similar study [25]. In the study, the mean and standard deviation of anxiety score in the intervention and control group were, respectively, $9.70 \pm 3.75$ and $11.43 \pm 4.51$. Considering an alpha of 0.05 , a power of $90 \%, \beta=0.10$ and $d=3$, sample size was 40 patients per group; a total of 80 participants.

\section{Randomization method and allocation concealment}

Each patient scheduled for angiography who meets our inclusion criteria was asked to participate in the study. Then the participants were asked to fill out the demographic questionnaire. We recorded the number of patients who refused to participate in the study (Fig. 1).

Participants were randomly assigned to one of the two groups of intervention (VR) or control (no intervention). Randomization was carried out using the block method. Blocks of four were used to maintain proportional allocation between the experimental and the control group throughout the study. The randomization list was created using specific software: whoever assigned the participants to the experimental and/or control groups did not take part in the creation of the randomization list and wasn't aware of its contents. For the randomization and assigning of the participants to the experimental and control groups, we used opaque envelopes. The envelopes were only opened by the nurse carrying out the intervention, after receiving consent from the participants involved in the study.

\section{Intervention and procedure}

Sixty candidates for coronary artery angiography from the cardiac center of Heshmat hospital in Rasht city (A northern city in Iran) took part in this study in two intervention and control groups (30 participants in each group). First, the participants were assessed in terms of the eligibility criteria. Next, the participants were instructed to study objectives and informed consent was obtained. 10 min before the start of coronary artery angiography, the first pre-intervention assessment was carried out. The anxiety level of the participants using STAI as well as their vital signs including; heart rate, respiratory rate, and blood pressure were measured as objective measures of anxiety immediately before the intervention in the two study groups. Blood pressure was measured using an Easy Life hand-held sphygmomanometer in a supine, right-hand position. Heart rate and respiration rate were measured with a digital watch made by CASIO. Then the intervention was done for the participants in the intervention group.

Before the start of the angiography, the subjects viewed a 5-min natural scene that was filmed at various natural locations and landscapes such as the beach, mountains, waterfalls, rivers with pleasant sounds by a VR camera. The sounds included soft music, birdsong, and waterfall sounds. A virtual reality video headset made by Remix company which had the ability to change the 360-degree angle of view at the same time as changing the position of the patient's head was used for playing VR video. Also, a Huawei mobile phone and a headphone were used to play the distraction music concurrent with virtual reality film play-back. At the end of the 5-min VR session, subjects were asked to fill out the STAI again and the vital signs were assessed for the second time. The intervention was done only in the intervention group in a private silent room. No intervention and placebo were used for patients of the control group. They completed the study questionnaire at similar times as the intervention group.

\section{Data analysis}

Data were analyzed using SPSS version 24.0 software (SPSS Inc.). Chi-square test was used to assess demographic differences between the two groups. Paired samples and independent sample $t$ tests were used to compare the level of state anxiety. The statistical significance was set to 0.05 .

\section{Ethical consideration}

This study was approved by the Ethics Committee of Guilan University of Medical Sciences, Rasht, Iran, with the ethical code of IR.GUMS.REC.1397.369. In addition, the study was registered in the Iranian Registry of Clinical Trials with the code of IRCT20140515017693N3. Written informed consent forms were signed by all participants as well as the aim of the study was described to all participants. Moreover, they were ensured that the study was voluntary and they could withdraw from the study at any time. 


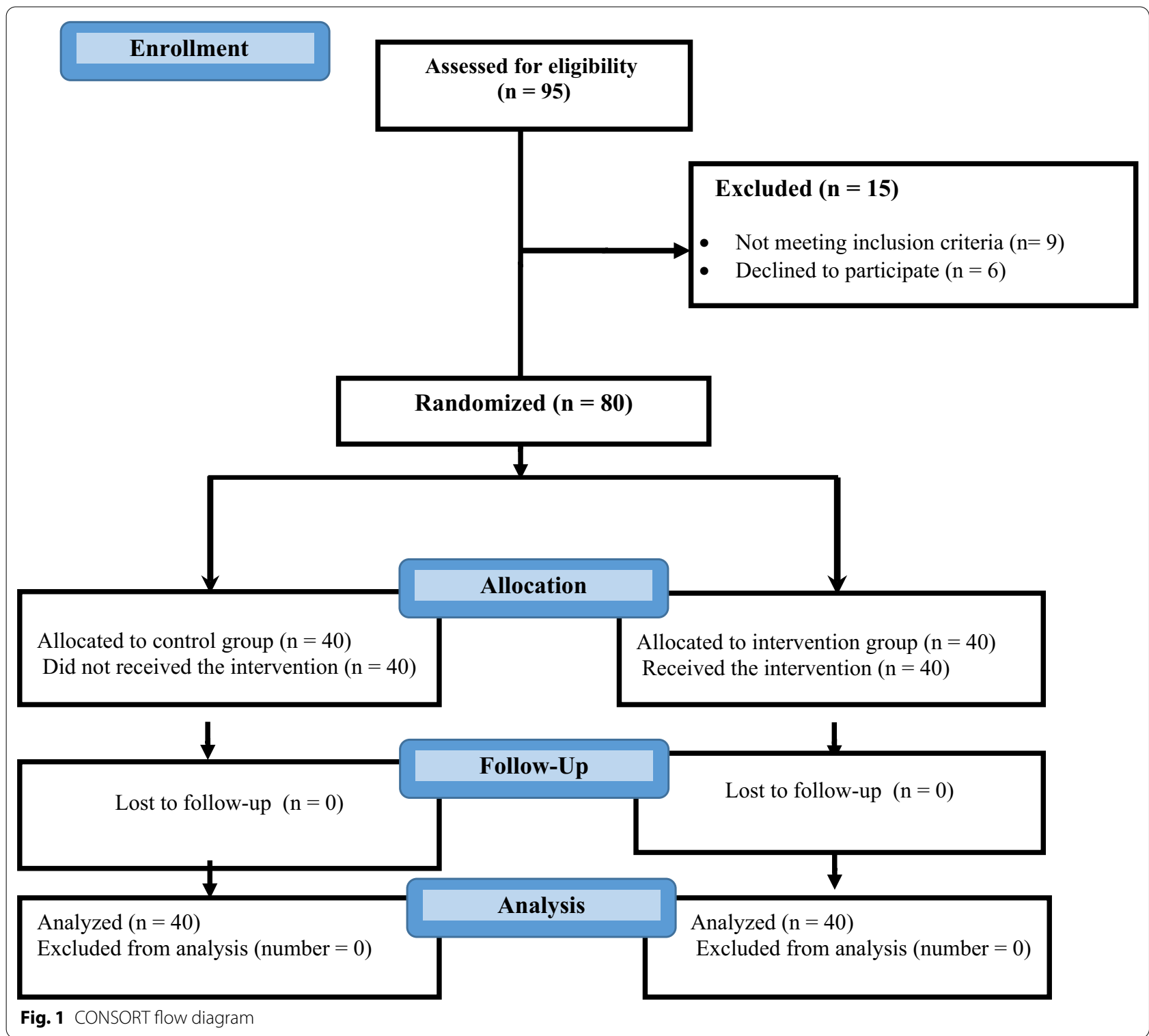

\section{Results}

We evaluated a total of 95 candidates of coronary artery angiography for eligibility, of whom 15 patients (15.8\%) failed to meet inclusion criteria. The excluded patients were ineligible due to respiratory problems $(33.3 \%)$, chest pain $(40 \%)$, being prone to vomiting $(6.7 \%)$, being too debilitated (13.3\%), and injury to face (6.7\%). Finally, 40 patients were allocated to each group. The participant flow is present in (Fig. 1).

The majority of participants were male $(71.25 \%)$ and married (76.25\%). The educational level of the majority of participants was diploma (30\%). The Mean \pm SD age of them in the intervention and control groups was $50.95 \pm 4.120$ and $52.08 \pm 4.002$ years, respectively.
The results of the Chi-square and independent $t$ test revealed no significant differences among the two groups with regard to demographic characteristics (Table 1).

The majority of the patients had no history of heart disease $(86.25 \%)$ and $76.25 \%$ were candidates for angiography due to chest pain. There were no significant differences among the two groups in the clinical characteristics and the groups were homogenous (Table 2).

At baseline, no significant differences were reported regarding anxiety scores between the two groups. However, the comparison of the anxiety scores after the intervention revealed a statistically significant difference in the two groups $(p=0.002)$. There also was 
Table 1 The demographic characteristics of the participants in the studied groups

\begin{tabular}{|c|c|c|c|}
\hline \multirow[t]{2}{*}{ Variables } & \multicolumn{2}{|l|}{ Groups } & \multirow[t]{2}{*}{$p$ value } \\
\hline & $\begin{array}{l}\text { Intervention } \\
\text { No (\%) }\end{array}$ & $\begin{array}{l}\text { Control } \\
\text { No (\%) }\end{array}$ & \\
\hline \multicolumn{4}{|l|}{ Sex } \\
\hline Male & $32(80)$ & $25(62.5)$ & \multirow[t]{2}{*}{$0.083^{*}$} \\
\hline Female & $8(20)$ & $15(37.5)$ & \\
\hline \multicolumn{4}{|l|}{ Marital statues } \\
\hline Single & $7(17.5)$ & $5(12.5)$ & \multirow[t]{3}{*}{$0.233^{*}$} \\
\hline Married & $29(72.5)$ & $32(80)$ & \\
\hline Divorced & $3(10)$ & $3(7.5)$ & \\
\hline \multicolumn{4}{|l|}{ Educational level } \\
\hline Illiterate & $1(2.5)$ & $3(7.5)$ & \multirow[t]{6}{*}{$0.611^{*}$} \\
\hline Under diploma & $12(30)$ & $10(25)$ & \\
\hline Diploma & $12(30)$ & $12(30)$ & \\
\hline Associate degree & $6(15)$ & $4(10)$ & \\
\hline Baccalaureate & $6(15)$ & $10(25)$ & \\
\hline Master's degree and higher & $3(7.5)$ & $1(2.5)$ & \\
\hline \multicolumn{4}{|l|}{ Occupation } \\
\hline Worker & $6(15)$ & $9(22.5)$ & \multirow[t]{5}{*}{$0.626^{*}$} \\
\hline Officeholder & $8(20)$ & $7(17.5)$ & \\
\hline Self-employment & $15(37.5)$ & $18(45)$ & \\
\hline Housekeeper & $10(25)$ & $5(12.5)$ & \\
\hline Retired & $1(2.5)$ & $1(2.5)$ & \\
\hline $\begin{array}{l}\text { Age } \\
\text { Mean } \pm \text { SD }\end{array}$ & $4.002(52.08)$ & $4.120(50.95)$ & $0.219^{* *}$ \\
\hline \multicolumn{4}{|l|}{ Place of residence } \\
\hline Urban area & $67.5(27)$ & $77.5(31)$ & \multirow[t]{2}{*}{$0.317^{*}$} \\
\hline Rural area & $32.5(13)$ & $22.5(9)$ & \\
\hline \multicolumn{4}{|l|}{ Type of insurance } \\
\hline Health insurance & $3(7.5)$ & $5(12.5)$ & \multirow[t]{5}{*}{$0.359^{*}$} \\
\hline Social security insurance & $21(52.5)$ & $26(65)$ & \\
\hline Rural health insurance & $13(32.5)$ & $8(20)$ & \\
\hline Army insurance & $3(7.5)$ & $1(2.5)$ & \\
\hline Without insurance & $0(0)$ & $0(0)$ & \\
\hline \multicolumn{4}{|l|}{ Complementary insurance } \\
\hline Yes & $2(5)$ & $4(10)$ & \multirow[t]{2}{*}{$0.396^{*}$} \\
\hline No & $38(95)$ & $36(90)$ & \\
\hline \multicolumn{4}{|l|}{ Experience of using virtual reality } \\
\hline Yes & $0(0)$ & $0(0)$ & \multirow[t]{2}{*}{-} \\
\hline No & $40(100)$ & $40(100)$ & \\
\hline
\end{tabular}

${ }^{*}$ Chi-square test

**Independent $t$ test

a significant decrease in intergroup anxiety score $(p<0.01)$ in the intervention group after the intervention (Table 3).

A statistically significant difference was revealed in the mean heart rate after the intervention among the two groups $(p=0.035)$. In the intervention group, the paired $t$
Table 2 The clinical characteristics of the participants in the study groups

\begin{tabular}{|c|c|c|c|}
\hline \multirow[t]{2}{*}{ Variables } & \multicolumn{2}{|l|}{ Groups } & \multirow[t]{2}{*}{$p$ value } \\
\hline & $\begin{array}{l}\text { Intervention } \\
N(\%)\end{array}$ & $\begin{array}{l}\text { Control } \\
N(\%)\end{array}$ & \\
\hline \multicolumn{4}{|l|}{ History of cardiac diseases } \\
\hline Yes & $15(6)$ & $12.5(5)$ & $0.745^{*}$ \\
\hline No & $85(34)$ & $87.5(35)$ & \\
\hline \multicolumn{4}{|l|}{ Reasons for referral } \\
\hline Chest pain & $75(30)$ & $77.5(31)$ & $0.841 *$ \\
\hline Arrhythmia & $10(4)$ & $10(4)$ & \\
\hline Tachycardia & $7.5(3)$ & $5(2)$ & \\
\hline Abnormal ECG & $5(2)$ & $7.5(3)$ & \\
\hline Other factors & $2.5(1)$ & $0(0)$ & \\
\hline \multicolumn{4}{|l|}{ Type of admission } \\
\hline Elective & $75(30)$ & $65(26)$ & $0.329^{*}$ \\
\hline Emergency referral & $25(10)$ & $35(14)$ & \\
\hline $\begin{array}{l}\text { Days of hospitalization } \\
\text { Mean } \pm S D\end{array}$ & $1.297(2.60)$ & $1.392(2.90)$ & $0.322^{* *}$ \\
\hline
\end{tabular}

test showed a significant decrease in the mean heart rate $(p=0.001)$ and systolic blood pressure $(p=0.016)$ from pre- to post-intervention (Table 4 ).

\section{Discussion}

To the best of our knowledge, this is the first study to investigate the effect of VR on reducing anxiety in candidates for coronary angiography in Iran. The findings revealed virtual reality distraction is effective to reduce anxiety before coronary artery angiography. There was a significant difference between the two groups regarding the mean score of anxiety after the intervention. Also, the reduction from baseline to post-intervention anxiety for the VR group was significantly greater than in the control group.

These results are consistent with other research that used VR to reduce anxiety in patients undergoing coronary artery angiography and showed that the level of anxiety in the patients decreased significantly after the intervention [25, 26]. Morgan et al. demonstrated that an immersive VR experience improves patient familiarity with cardiac catheterization and can reduce preprocedural anxiety [26]. It seems that VR can divert the patients' attention with attractive audiovisual materials, which dispels the patient's anxiety before coronary angiography.

The study of Tadayonfar et al. indicated auditory guided imagery can effectively reduce the level of anxiety in hospitalized patients before cardiac angiography 
Table 3 Scores of situational anxiety in the intervention and control group at baseline and after intervention

\begin{tabular}{llll}
\hline & Intervention group & Control group & ${ }^{*} \boldsymbol{p}$ value \\
\hline Before intervention (baseline) & $3.144(14.9)$ & $3.233(14.4)$ & $0.507^{*}$ \\
After intervention & $2.131(13.07)$ & $3.529(15.1)$ & $0.002^{*}$ \\
${ }^{* *} p$ value & $0.010^{* *}$ & $0.292^{* *}$ & \\
\hline
\end{tabular}

*Independent samples $T$ test

**Paired $t$ test

Table 4 Comparison of mean values of vital sign before and after the intervention in the two study groups

\begin{tabular}{|c|c|c|c|}
\hline & Intervention group & Control group & ${ }^{*} p$ value \\
\hline \multicolumn{4}{|l|}{ Heart rate (min) } \\
\hline Before intervention & (5.334) 71.6 & $7.21(4.562)$ & 0.736 \\
\hline After intervention & $69.43(4.230)$ & $7.4(4.224)$ & 0.035 \\
\hline${ }^{* *} p$ value & 0.001 & 0.362 & \\
\hline \multicolumn{4}{|l|}{ Respiratory rate (min) } \\
\hline Before intervention & $18.93(0.997)$ & $18.58(1.466)$ & 0.216 \\
\hline After intervention & $18.68(0.829)$ & $18.53(1.396)$ & 0.561 \\
\hline${ }^{* *} p$ value & 0.115 & 0.728 & \\
\hline \multicolumn{4}{|c|}{ Systolic blood pressure $(\mathrm{mmHg})$} \\
\hline Before intervention & $135.63(20.730)$ & $130(20.646)$ & 0.238 \\
\hline After intervention & (18.115) 125.25 & $12 /(20.121)$ & 0.522 \\
\hline${ }^{* *} p$ value & 0.016 & 0.677 & \\
\hline \multicolumn{4}{|l|}{ Diastolic blood pressure } \\
\hline Before intervention & $79(9.001)$ & $78.2(8.883)$ & 0.709 \\
\hline After intervention & $(10.025) 76.63$ & (10.252) 77.3 & 0.742 \\
\hline${ }^{* *} p$ value & 0.235 & 0.688 & \\
\hline
\end{tabular}

*Independent samples $T$-test

**Paired $t$-test

[27]. Guided imagery has been defined as a directed, deliberate daydream that uses all senses to create a state of relaxation and well-being. It is similar to VR and can diminish the anxiety and pain in patients [28]. Considering the similarity of guided imagery with VR, it can be acknowledged that the results are consistent with the present study.

Although researchers have encountered few studies about the effect of VR on pre-angiographic anxiety, there are several similar studies in other fields about the effectiveness of VR and the various audio-visual interventions which are the main mechanism of VR. In this regard, there are studies that are either similar or inconsistent with the findings of the present study.

Brown and Foronda introduced VR as a novel intervention that can reduce perioperative anxiety for patients undergoing surgical and non-surgical procedures [23]. Ganry et al. showed that VR is an effective complementary technique to manage preoperative stress as it allows patients to be immersed in a relaxing environment and is a safe way to reduce stress levels [29].

Some studies in other fields also reported a positive effect of virtual reality in the reduction of anxiety and other psychological symptoms such as stress and depression in patients with cancer [30] and the endoscopic candidates [31].

Contrary to the results of the current study, previous research in china among patients with coronary artery disease has not reported a reduction in anxiety following an auditory and sensory stimulation which was similar to the VR [32]. It seems that the inconsistency of the findings is due to the lack of use of visual stimulation.

The results of the present study indicated a significant reduction in the heart rate and blood pressure after the intervention in the intervention group in comparison with the control group.

The results of the other study that investigated the effect of an auditory relaxation technique on anxiety and physiologic indices in patients before angiography showed a significant decrease in the anxiety score, heart rate, and blood pressure in the intervention group [32] that is consistent with our findings. Decreased blood pressure after relaxation and distraction is caused by muscle relaxation, decreased vascular resistance, and decreased sympathetic system activity in patients.

This study is the first research to examine the effect of virtual reality exposure in candidates of coronary artery angiography in Iran. In order to improve the generalizability of the results, we recommend more studies for the development of evidence-based practice.

There are some strengths and limitations of the study. One of the strengths of this study was that it consisted of two groups. However, the short duration of the intervention and the follow-up were the limitations of this study. Similar to the other study and innovations in the field of facilitators of non-invasive care and treatment [33], this study was conducted for the first time in Iran and the impact of virtual reality on the pre-angiography anxiety was confirmed as an innovation. 


\section{Conclusions}

The results of this study indicated a significant difference between the two groups with respect to the mean score of anxiety, heart rate, and blood pressure after the intervention. Implementation of the VR distraction protocol as a practical non-invasive method could effectively reduce pre-angiography anxiety and its indices in the angiography candidates. Further studies are needed to more accurately assess its long-term effects in reducing anxiety and complications caused by angiography.

\section{Abbreviations \\ CHD: Coronary heart disease; VR: Virtual reality; STAI: Short form of Spielberger state-trait anxiety inventory.}

\section{Acknowledgements}

This study is performed in the form of a master's dissertation in nursing with Grant Number 1311816421. It was registered in Iran Randomized Clinical Trial with code: IRCT201 4051501 7693N3, and ethical code IR.GUMS.REC.1397.369. The authors appreciate the financial support of the Deputy of Research and Technology of Guilan University of Medical Sciences (GUMS). Also, we thank all the participants.

\section{Authors' contributions}

$M K, M R Y, E P$, and MP contributed to conceptualization; MK, MRY, EP, and MP contributed to methodology; Z AR and MK contributed to formal analysis and investigation; MP contributed to writing - original draft preparation; MRY and MP contributed to writing — review and editing; MK contributed to data collection; MK, MRY, and EP provided the resources; MRY and EP contributed to supervision. All authors read and approved the final manuscript.

\section{Funding}

This work was supported by Guilan University of Medical Sciences with Grant Numbers 1311816421.

\section{Availability of data and materials \\ Not applicable.}

\section{Declarations}

\section{Ethics approval and consent to participate}

This study was approved by the Ethics Committee of Guilan University of Medical Sciences, Rasht, Iran with the ethical code of IR.GUMS.REC.1397.369. In addition, the study was registered in the Iranian Registry of Clinical Trials with the code of IRCT20140515017693N3. The study was performed in accordance with the 1964 Helsinki declaration and its later amendments or comparable ethical standards. Written informed consent forms were signed by all participants as well as the aim of the study was described to all participants.

\section{Consent for publication}

Not applicable.

\section{Competing interests}

All authors have none to declare.

\begin{abstract}
Author details
'Department of Nursing, Shahid Beheshti School of Nursing and Midwifery, Guilan University of Medical Sciences, Rasht, Islamic Republic of Iran. ${ }^{2}$ Department of Biostatistics, Medical School, Guilan University of Medical Sciences, Rasht, Islamic Republic of Iran. ${ }^{3}$ Shahid Dr. Beheshti Nursing and Midwifery School, Hamidyan suburb,Shahid Beheshti Ave., Guilan, Rasht, Islamic Republic of Iran.
\end{abstract}

\section{References}

1. Qin S, Gu Y, Song T (2019) Effect of peer support on patient anxiety during the coronary angiography or percutaneous coronary intervention perioperative period: a protocol for a systematic review and meta-analysis of randomised controlled trials. BMJ Open 10(3):e031952. https://doi. org/10.1136/bmjopen-2019

2. Benjamin EJ, Blaha MJ, Chiuve SE, Cushman M, Das SR, Deo R et al (2017) Heart disease and stroke statistics-2017 update: a report from the American Heart Association. Circulation 135(10):e146-e603. https://doi.org/10. 1161/CIR.0000000000000485

3. Talaei M, Sarrafzadegan N, Sadeghi M, Oveisgharan S, Marshall T, Thomas GN et al (2013) Incidence of cardiovascular diseases in an Iranian population: the Isfahan Cohort Study. Arch Iran Med 16(3):0

4. Nekouei ZK, Yousefy A, Manshaee G, Nikneshan S (2011) Comparing anxiety in cardiac patients candidate for angiography with normal population. ARYA Atherosclerosis 7(3):93-96

5. Moradi T, Adib HM (2015) State and trait anxiety in patients undergoing coronary angiography. Int J Hosp Res 4(3):123-128

6. Habibzadeh H, Milan ZD, Radfar M, Alilu L, Cund A (2018) Effects of peerfacilitated, video-based and combined peer-and-video education on anxiety among patients undergoing coronary angiography: randomised controlled trial. Sultan Qaboos Univ Med J 18(1):e61. https://doi.org/10. 18295/squmj.2018.18.01.010

7. Assari S, Zandi H, Ahmadi K, Saleh DK (2017) Extent of coronary stenosis and anxiety symptoms among patients undergoing coronary angiography. J Tehran Univ Heart Center 12(4):155-159

8. Asgari MR, Barari L, Ghorbani R, Darabiyan M, Eskandarian R, Ghods AA (2019) Anxiety levels in patients candidate for coronary artery angiography. Koomesh 21(3):437-443 ((Persian))

9. Gu G, Zhou Y, Zhang Y, Cui W (2016) Increased prevalence of anxiety and depression symptoms in patients with coronary artery disease before and after percutaneous coronary intervention treatment. BMC Psychiatry 16(1):1-9. https://doi.org/10.1186/s12888-016-0972-9

10. Aboalizm SE, El Gahsh NF, Masry SE (2016) Effect of early nursing preparation on anxiety among patients undergoing cardiac catheterization. Am J Nurs 5(5):222-231. https://doi.org/10.11648/j.ajns.20160505.17

11. Jamshidi N, Abaszade A, Najafi-Kaliani M (2012) Stress, anxiety and depression of patients before coronary angiography. Zahedan J Res Med Sci (Tabib-e-Shargh) 13(1) (Persian)

12. Vardanjani MM, Alavi NM, Razavi NS, Aghajani M, Azizi-Fini E, Vaghefi SM (2013) A randomized-controlled trial examining the effects of reflexology on anxiety of patients undergoing coronary angiography. Nurs Midwif Stud 2(3):3-9. https://doi.org/10.5812/nms.12167

13. Riener $R$, Harders M (2012) Introduction to virtual reality in medicine. In: Virtual reality in medicine. Springer, London

14. Tytler J (2020) Encyclopædia Britannica 2020 January 07, 2020. https:// www.britannica.com/biography/James-Tytler

15. Arjmandnia A, Maleki F, Sharifi H, Heydari K (2017) Investigating the effectiveness of physical education program on improving the social competence of mentally retarded students in the pre-vocational course. Except Educ 2(145):29-38 ((Persian))

16. Bohil CJ, Alicea B, Biocca FA (2011) Virtual reality in neuroscience research and therapy. Nat Rev Neurosci 12(12):752-762

17. Noben L, Goossens SMTA, Truijens SEM, Van Berckel MMG, Perquin CW, Slooter GD et al (2019) A virtual reality video to improve information provision and reduce anxiety before cesarean delivery: randomized controlled trial. JMIR Mental Health 6(12):e15872.

18. Dahlquist LM, Weiss KE, Dillinger Clendaniel L, Law EF, Ackerman CS, McKenna KD (2008) Effects of videogame distraction using a virtual reality type head-mounted display helmet on cold pressor pain in children. J Pediatr Psychol 34(5):574-584. https://doi.org/10.1093/jpepsy/jsn023

19. Frere CL, Crout R, Yorty J, McNeil DW (2001) Effects of audiovisual distraction during dental prophylaxis. J Am Dental Assoc 132(7):1031-1038. https://doi.org/10.14219/jada.archive.2001.0309

20. Umezawa S, Higurashi T, Uchiyama S, Sakai E, Ohkubo H, Endo H et al (2015) Visual distraction alone for the improvement of colonoscopyrelated pain and satisfaction. World J Gastroenterol WJG 21(15):4707. https://doi.org/10.3748/wjg.v21.i15.4707

21. Kerimoglu B, Neuman A, Paul J, Stefanov DG, Twersky R (2013) Anesthesia induction using video glasses as a distraction tool for the management 
of preoperative anxiety in children. Anesth Analg 117(6):1373-1379. 10.213/ANE.0b013e3182a8c18f

22. Alshatrat SM, Alotaibi R, Sirois M, Malkawi Z (2019) The use of immersive virtual reality for pain control during periodontal scaling and root planing procedures in dental hygiene clinic. Int J Dental Hygiene 17(1):71-76. https://doi.org/10.1111/idh.12366

23. Brown K, Foronda C (2020) Use of virtual reality to reduce anxiety and pain of adults undergoing outpatient procedures. Informatics 7(3):36. https://doi.org/10.3390/informatics7030036

24. Marteau TM, Bekker H (1992) The development of a six-item short-form of the state scale of the Spielberger State-Trait Anxiety Inventory (STAI). Br J Clin Psychol 31(3):301-306. https://doi.org/10.1111/j.2044-8260.1992. tb00997.x

25. Bagheri-Nesami M, Shorofi SA, Zargar N, Sohrabi M, Gholipour-Baradari A, Khalilian A (2014) The effects of foot reflexology massage on anxiety in patients following coronary artery bypass graft surgery: a randomized controlled trial. Complement Ther Clin Pract 20(1):42-47. https://doi.org/ 10.1016/j.ctcp.2013.10.006

26. Morgan H, Gallagher SM (2019) 59 The effect of a virtual reality immersive experience upon anxiety levels in patients undergoing cardiac catheterisation: the virtual cath trial. Heart 105(Suppl 6):A50. https://doi.org/10. 1136/heartjnl-2019-BCS.57

27. Tadayonfar M, Foji S, Mohsenpour M, Rakhshanil M (2014) The effect of guided imagery on patients' anxiety undergoing cardiac catheterization. J Sabzevar Univ Med Sci 20(5):689-695 ((Persian))

28. Gonzales EA, Ledesma RJ, McAllister DJ, Perry SM, Dyer CA, Maye JP (2010) Effects of guided imagery on postoperative outcomes in patients undergoing same-day surgical procedures: a randomized, single-blind study. AANA J 78(3):181-188

29. Ganry L, Hersant B, Sidahmed-Mezi M, Dhonneur G, Meningaud J (2018) Using virtual reality to control preoperative anxiety in ambulatory surgery patients: a pilot study in maxillofacial and plastic surgery. J Stomatol Oral Maxillofac Surg 119(4):257-261. https://doi.org/10.1016/j.jormas.2017.12. 010

30. Aliakbari M, Alipor A, Ebrahimimoghadam H, Fekraty M (2017) The effect of virtual reality (VR) on psychological disorders in cancer caseses. Military Caring Sci 4(1):49-57 ((Persian))

31. Heidari M, Shahbazi S (2013) Effect of Quran and music on anxiety in patients during endoscopy. Knowl Health 8(2):67-70 ((Persian))

32. Taylor-Piliae RE, Chair S-Y (2002) The effect of nursing interventions utilizing music therapy or sensory information on Chinese patients' anxiety prior to cardiac catheterization: a pilot study. Eur J Cardiovasc Nurs 1(3):203-211. https://doi.org/10.1016/S474-5151(02)00037-3

33. Valsecchi O, Vassileva A, Cereda AF, Canova P, Satogami K, Fiocca L et al (2018) Early clinical experience with right and left distal transradial access in the anatomical snuffbox in 52 consecutive patients. J Invasive Cardiol 30(6):218-223

\section{Publisher's Note}

Springer Nature remains neutral with regard to jurisdictional claims in published maps and institutional affiliations.

\section{Submit your manuscript to a SpringerOpen ${ }^{\circ}$ journal and benefit from:}

- Convenient online submission

- Rigorous peer review

- Open access: articles freely available online

- High visibility within the field

- Retaining the copyright to your article

Submit your next manuscript at $\boldsymbol{\nabla}$ springeropen.com 